\title{
The endonuclease VIII-like proteins: new targets in the treatment of ischemic stroke?
}

\author{
Long-Xiu Yang ${ }^{1,2}$, Wei Wang ${ }^{3}$, Xiao Zhang ${ }^{2}$, Qi Zhu², Qing Zhao², Gang Zhao \\ ${ }^{1}$ Department of Neurology, The First Affiliated Hospital, Guangxi Medical University, Nanning 530021, Guangxi, China. \\ ${ }^{2}$ Department of Neurology, Xijing Hospital, The Fourth Military Medical University, Xi'an 710032, Shaanxi, China. \\ ${ }^{3}$ Department of Microbiology, University of Oslo, $\mathrm{N}$-0424 Oslo, Norway.
}

\section{A B S T R A C T}

Oxidative deoxyribonucleic acid (DNA) damage is one of the major causes of neuronal injury in ischemia. The endonuclease VIII-like (NEIL) DNA glycosylases have a specific role in recognition and removal of oxidative DNA damage. The NEIL family includes NEIL1, NEIL2, and NEIL3, that differ in substrate specificity, catalytic efficiency, and subcellular/tissue distribution. This opens for a situation-dependent phenotype in their absence. In this review, we will discuss the current knowledge on the involvement of the NEILs in ischemic stroke and discuss the potential of these enzymes to serve as new targets in the treatment of ischemic stroke.

Key words: Endonuclease VIII-like proteins, ischemic stroke, targets

\section{INTRODUCTION}

According to the World Health Organization health report, stroke is the leading cause of disability in adults and accounts for 5.5 million deaths worldwide, equivalent to $9.6 \%$ of all deaths. ${ }^{[1]}$ Ischemic stroke is the most common type of stroke, accounting for about $87 \%$ of all stroke events. ${ }^{[2]}$ Oxidative stress, which is a disturbance in the oxidant-antioxidant balance leading to the potential cellular damage, is widely recognized as one of the major factors contributing to the pathophysiologic progressing of the brain in an ischemic stroke. ${ }^{[3]}$ Oxidative stress is also known to play a role as a vital factor of ischemia reperfusion, which is one of the pathological events after ischemic brain. ${ }^{[4]}$ Oxidative stress not only could lead to structural changes of the proteins which can cause the loss of biological activity, but also create oxidative deoxyribonucleic acid (DNA) lesions in addition to damage to other cellular constituents. ${ }^{[5]}$ Oxidative

Corresponding Author: Prof. Gang Zhao,

Department of Neurology, Xijing Hospital, The Fourth Military Medical University, No. 169, Changle West Road,

$X^{\prime}$ 'an 710032, Shaanxi, China.

E-mail: zhaogang@fmmu.edu.cn

\begin{tabular}{|l|l|}
\hline \multicolumn{2}{|c|}{ Access this article online } \\
\hline Quick Response Code: & \\
\hline & Website: \\
\hline & Www.nnjournal.net \\
& DOI: \\
\hline
\end{tabular}

DNA damage can trigger cell death after the trauma, ${ }^{[6]}$ especially in neurons which are more susceptible to damage than astrocytes. ${ }^{[7]}$ Accumulated cell loss will gradually contribute to disease progression and eventually lead to poor prognosis in ischemic stroke. ${ }^{[8]}$ Maintaining genome integrity is essential for cell survival and the main DNA repair system for repairing oxidative DNA damage is base excision repair (BER) ${ }^{[9]}$ However, the exact impact of BER is still not fully understood, as most studies have been performed in models where BER is either present or absent. As it is well known that unbalanced BER is detrimental to the cell, one might speculate that suppressing full activation after ischemic insult could be beneficial to restore cell. It should be remembered that the killing period occurs after the stroke, during reperfusion when repair process is expected to be maximal. The DNA repairing capacity of BER may affect the survival rate of neurons and change the pathological outcome of ischemic stroke.

BER is initiated by DNA glycosylases that recognize and excise the damaged bases of DNA. ${ }^{[10]}$ Depending on the type of lesion the BER pathway is initiated

This is an open access article distributed under the terms of the Creative Commons Attribution-NonCommercial-ShareAlike 3.0 License, which allows others to remix, tweak, and build upon the work non-commercially, as long as the author is credited and the new creations are licensed under the identical terms.

For reprints contact: nn_editor001@nnjournal.net

Cite this article as: Yang LX, Wang W, Zhang X, Zhu Q, Zhao Q, Zhao G. The endonuclease VIII-like proteins: new targets in the treatment of ischemic stroke?. Neuroimmunol Neuroinflammation 2015;2:281-6.

Received: 24-04-2015; Accepted: 21-08-2015 
by one of 11 different DNA glycosylases including UNG1, UNG2, SUMUG1, thymine-DNA glycosylase, methyl-binding domain 4, methylpurine-DNA glycosylase, OGG1, muty glycosylase homologue, NTHL1, endonuclease VIII-like (NEIL) 1, NEIL2, and NEIL3. ${ }^{[11]}$ The subsequent pathway can divide into two sub-pathways: short-patch BER (SP-BER) and long-patch BER (LP-BER). ${ }^{[12]}$ The repair processes consist of five steps: excision of the base, incision, end processing, and repair synthesis, including gap filling and ligation. ${ }^{[11]}$ In SP-BER, a pol $\beta$-mediated single nucleotide incorporation is followed by strand ligation, catalyzed by the XRCC1/DNA ligase III complex. If BER is initiated by NEILs glycosylases, after $\mathrm{N}$-glycosidic hydrolysis the termini is catalyzed by $\beta, \delta$-elimination. Then the $3^{\prime}$-phosphate is cleaved by polynucleotide kinase, producing a $1 \mathrm{NT}$ gap with $3^{\prime}-\mathrm{OH}$ terminus. ${ }^{[13,14]}$ LP-BER is characterized by alternating flap endonuclease 1 cleavage and pols $\beta$ synthesis or the strand displacement DNA synthesis concerted by pols $\beta$ and $\delta / \varepsilon$. At last, the gap is sealed by DNA ligase I. ${ }^{[14]}$ OGG1, NTHL1, NEIL1, NEIL2, and NEIL3 are recognized to be the five major DNA glycosylases to remove oxidative base lesions. ${ }^{[10]}$ NEILs play a critical role in the repair of oxidative DNA damage. Accumulating evidence suggests that NEILs may relate to diseases in central nervous system, for example, ischemic stroke, neurodegeneration disease, and neurological autoimmune disease with consistent results. ${ }^{[15]}$ However, our understanding of the functions and potential uses of NEILs in ischemic stroke is still limited.

Thus, the purpose of this review is to summarize the current knowledge on the involvement of the NEILs in ischemic stroke and aim to search for a new target in the treatment of ischemic stroke.

\section{CHARACTERISTICS OF NEIL}

In 2002, several groups working independently worldwide discovered three genes in the mouse and human genomes encoding DNA glycosylases belonging to the Fpg/Nei superfamily and having a primary structure more similar to that of the NEIL protein. ${ }^{[16-19]}$ These proteins were named NEIL1, NEIL2, and NEIL3. ${ }^{[16-19]}$ The characteristics of human NEIL genes and proteins are shown in Table 1.
The discovery of these three new DNA glycosylases generated strong interests by scientists to investigate their biochemical functions and the corresponding mechanisms. We summarize the substrate specificities of NEILs in Table 2.

Interestingly, NEILs substrates largely overlap with the OGG1 and NTHL1 substrate spectra indicates that NEILs may have a role in DNA repair that is unique to other DNA glycosylases.

NEIL1, NEIL2, and NEIL3 can also be distinguished from each other by the preferred lesions in different DNA structures, which demonstrate their unique biological roles in the regulation of cell cycle. NEIL1 interacts with proliferating cell nuclear antigen (PCNA) and PCNA can stimulates NEIL1 activity suggesting its special role in replication. ${ }^{[20]}$ NEIL2 is involved in repairing oxidized bases in the transcribed genes of mammalian cells, in particular, lesions in the mutagenic cytosine oxidation product 5-hydroxyuracil of the transcribed strand. In this function, NEIL2 associates with ribonucleic acid (RNA) polymerase II and the transcriptional regulator heterogeneous nuclear ribonucleoprotein-U. ${ }^{[21]}$ The NEIL3 repairs lesions in DNA with single-stranded regions ${ }^{[22,23]}$ and this phenomenon may demonstrate its potential role in cell proliferating, embryonic development, and neurogenesis.

\section{NEIL1 expression patterns}

Many studies have aimed at clarifying the expression patterns of NEIL1. The NEIL1 shows ubiquitous expression in all tissues examined in a human, including the brain. ${ }^{[17-19]}$ More specifically, NEIL1 was identified in all brain regions analyzed in human, and especially in the cerebellum, neocortex, and hippocampus. ${ }^{[24]}$ Rolseth et al. ${ }^{[24]}$ showed that expression of NEIL1increases with age by in situ hybridization studies in mouse brain. Englander and $\mathrm{Ma}^{[25]}$ found out that the expression of NEIL1 in the mature brain increases 1.5-2.5-fold compared to the embryonic brain.

The NEIL1 activity has also been detected in mitochondria in the brain. ${ }^{[26]}$ In accordance with its age-dependent expression, the activity in mitochondria also correlates with age, but with important differences: mitochondrial NEIL1 in the

\begin{tabular}{lccccccccc}
\hline Table I: The characteristics of human NEIL genes and proteins & & & & & \\
Gene & $\begin{array}{c}\text { Gene length } \\
\text { nucleotides }\end{array}$ & $\begin{array}{c}\text { Number } \\
\text { of exons }\end{array}$ & $\begin{array}{c}\text { Coding sequence, } \\
\text { nucleotides }\end{array}$ & $\mathbf{C L}$ & $\begin{array}{c}\text { Amino } \\
\text { acids }\end{array}$ & $\begin{array}{c}\text { Protein } \\
\text { size (kDa) }\end{array}$ & SL & CCD & C/I \\
\hline NEIL1 & 8258 & 9 & 1173 & $15 q 24.2$ & 390 & 43.6 & N and M & Yes & I \\
NEIL2 & 17683 & 4 & 999 & $8 p 23.1$ & 332 & 36.7 & Nand M & Yes & I \\
NEIL3 & 53102 & 10 & 1818 & $4 q 34.3$ & 605 & 67.7 & N & Yes & I \\
\hline
\end{tabular}

CL: chromosomal location; SL: subcellular location; N: nucleus; M: mitochondria; CCD: cell cycle dependent; C/I: constitutive or inducible protein 
Table 2: The substrates specificities of NEILs

\begin{tabular}{|c|c|c|c|c|}
\hline Name & $\begin{array}{l}\text { Mono-I } \\
\text { bifurcate }\end{array}$ & Base & Substrates specificity & DNA \\
\hline NEIL1 & B & dines/ & $\begin{array}{l}\mathrm{Sp}, \mathrm{Gh}, \mathrm{DHT}, \mathrm{DHU}, \mathrm{Tg}, \\
\text { 5-OHC, 5-OHU, 8-oxoG, } \\
\text { FapyG, and FapyA }\end{array}$ & $\begin{array}{l}\text { ssDNA/ } \\
\text { dsDNA }\end{array}$ \\
\hline NEIL2 & B & $\begin{array}{l}\text { Pyrimidines/ } \\
\text { purines }\end{array}$ & $\begin{array}{l}\mathrm{Sp}, \mathrm{Gh}, \mathrm{DHT}, \mathrm{DHU}, \mathrm{Tg}, \\
\text { 5-OHC, 5-OHU, and } \\
\text { 8-oxoG }\end{array}$ & $\begin{array}{l}\text { ssDNA/ } \\
\text { dsDNA }\end{array}$ \\
\hline NEIL3 & $\mathrm{M} / \mathrm{B}$ & $\begin{array}{l}\text { Pyrimidines/ } \\
\text { purines }\end{array}$ & $\begin{array}{l}\text { Sp, Gh, FapyG, and } \\
\text { FapyA }\end{array}$ & ssDNA \\
\hline
\end{tabular}

Sp: spiroiminodihydantoin; Gh: guanidinohydantoin; DHT: 5,6-dihydrothymine; DHU: 5,6-dihydrouracil; FapyG: 2,6-diamino-4-hydroxy-5-formamidopyrimidine; FapyA: 4,6-diamino-5-formamidopyrimidine; 5-OHC: 5-hydroxycytosine;

5-OHU: 5-hydroxyruacil; Tg: thygly; 8-oxoG: 8-oxoguanine; ssDNA: singlestranded DNA; dsDNA: double-stranded DNA

cortex region is age-dependent and maximal in the middle-age. However, in the hippocampus, one of the neurogenic regions in the brain, mitochondrial NEIL1 is stable throughout a lifetime. By using a 5-OHdU containing bubble substrate, Gredilla et al. ${ }^{[26]}$ found that mitochondrial NEIL1 activity showed an age-related change in the cortex with a significant peak at middle-age in the cortical region, but not in the hippocampus where no significant change occurred during the lifespan. The distinct age-dependent, subcellular- and tissue-distribution suggests that the role of NEIL1 is strongly connected to site-specific conditions.

In conclusion, the widespread expression of NEIL1in mammals demonstrated its unique role in the maintenance of gene integrity.

\section{NEIL2 expression patterns}

By using Northern analysis, NEIL2 was found to have the highest expression in the skeletal muscle and testis, moderate expression levels in the brain and heart and a very low level expression in placenta, lung, liver, kidney, and pancreas. ${ }^{[17]}$ The same study also showed that NEIL2 mRNA level did not significantly change through the cell cycle and that NEIL2 was predominantly mitochondrially localized. ${ }^{[17]}$ NEIL2 expression had also been detected in embryonic, neonatal, and adult rat brain and the expression level increased 1.5-2.5-fold in the mature rat brain compared to the embryonic brain, which is the same as NEIL1. ${ }^{[25]}$ In the human brain, NEIL2 showed a widespread expression pattern in accordance with OGG1, NTH1, and NEIL1. ${ }^{[24]}$ Rolseth et al. ${ }^{[24]}$ also found that NEIIL2 had a similar expression pattern as NEIL1 by detecting expression of NEIL2 in mouse brain during postnatal development, but with a slightly increased expression with age. In summary, NEIL2 has a widespread expression pattern in human and rodent and the subcellular localization of NEIL2 is in mitochondria and in the nucleus. This distribution and tissue specificity of NEIL2 suggest that it may serve as a critical factor to maintain the integrity of the genome lifelong.

\section{NEIL3 expression patterns}

Compared to NEIL1 and NEIL2, The NEIL3 has a very distinct expression pattern. ${ }^{[18]}$ Among all the human adult tissues, NEIL3 is only expressed at detectable levels in the thymus and testis, which indicates that NEIL3 might have a specialized function associated with proliferative capacity. Torisu et al., ${ }^{[27]}$ studied the expression level of NEIL3 in human but only found NEIL3 expression in thymus. In mouse tissue, NEIL3 mRNA was expressed in thymus, spleen, and bone marrow. ${ }^{[27]}$ By developing NEIL3-null mice, Torisu found that NEIL3-null mice looked healthy for at least 24 weeks after birth. Furthermore, NEIL3-null male mice were viable and fertile. According to these findings, Torisu et al. ${ }^{[27]}$ concluded that NEIL3 was not required for maintenance of testis function but had a potential function in the development of the hemopoietic system. In the central nervous system, NEIL3 mRNA expression has been investigated in different brain areas of human adults by Northern blot hybridization. ${ }^{[24]}$ NEIL3 could not be detected in any brain region of adult humans. In contrast, by studying the expression of NEIL3 in mouse brain during postnatal development, NEIL3 transcripts can be observed in the subventricular zone (SVZ), hilus of the hippocampal formation, the rostral migratory stream, and the Purkinje cell of the cerebellum in P3 mice brain. In 1-month-old mouse brain, the NEIL3 was detected in layer $\mathrm{V}$ of the neocortex and only in a few cells in the SVZ and in the 1-year-old brain only in layer $\mathrm{V}$ of the neocortex. These results indicate that the expression of NEIL3 declines with age, and it is selectively expressed in brain regions associated with neurogenesis. NEIL3 expression has also been detected in regions rich in neurogenesis in the embryonic brain ${ }^{[28]}$ and in two recent studies NEIL3-null models showed a decreased differentiation potential of neural stem cells. ${ }^{[29,30]}$ NEIL3-null mice showed learning and memory deficits and reduced anxiety-like behavior, and synaptic irregularities in hippocampal neurons. ${ }^{[31]}$ All together, these results suggest that NEIL3 may have a specific role in neurogenesis in the central nervous system.

The NEIL3 has been shown to be highly expressed in many tumor tissues, which supports the notion that NEIL3 might be associated with proliferation capacity. ${ }^{[32-34]}$

Regarding the subcellular localization of NEIL3, two studies have consistently found that NEIL3 is expressed in the cell nucleus. ${ }^{[18,27]}$ Two additional 
studies showed that NEIL3 was cell cycle-regulated with the highest expression in the G2 phase. ${ }^{[32,33]}$ Thus far, NEIL3 proteins have not been found in the mitochondria. ${ }^{[23]}$

In conclusion, distribution of NEIL3 is very different from other DNA glycosylases which suggests a special function of NEIL3 in a mammal. In the central nervous system, NEIL3 expression in both human and mouse brain has been localized to regions where neurogenesis takes place. NEIL3 seems to be upregulated in tumor tissues compared to normal tissues. In summary, the expression patterns of NEIL3 suggest that mammalian NEIL3 seems to be highly expressed in cells that have high proliferative potential.

\section{THE NEIL AND ISCHEMIC STROKE}

\section{NEIL1}

The interest in the relationship between NEILs and stroke arises from the work done by Rolseth et al. ${ }^{[35]}$ By observing BER activities in organotypic hippocampal slice culture exposed to oxygen and glucose deprivation, the authors found that CA1 has a lower capacity than CA3/FD in base lesions removal under basal conditions, which may be correlated with the low expression levels of both NEIL1 and NEIL2. ${ }^{[35]}$ This study has not only demonstrated the reasons why CA1 was vulnerable to ischemic stroke but also revealed the potential unique role that DNA glycosylases might play in ischemic stroke. ${ }^{[35]} \mathrm{By}$ addressing the effect of hyperoxic reoxygenation and therapeutic hypothermia on the development of brain damage after asphyxia in newborn pigs, Dalen et al. ${ }^{[36]}$ found out that NEIL1 is significantly downregulated in the hippocampus, cortex, striatum, and liver upon hypothermia without any detective effect on the accumulation of oxidative DNA damage in genomic DNA. In addition, like OGG1, NEIL1 expression in the brain is unaffected by hyperoxia. A recent study by Canugovi et al. ${ }^{[37]}$ demonstrated that NEIL1 can be linked to changes in ischemic stroke. Due to the increasing brain damage caused by reducing the incision capacity on a 5-hydroxyuracil-containing bubble substrate, NEIL1 gene knockout mice exhibited impaired memory retention in a water maze test, but no abnormalities in motor performance, anxiety, or fear conditioning. These results indicate that NEIL1 plays an important role in learning and memory and in the protection of neurons against ischemic injury. Interestingly, NEIL1 gene knockout mice display a specific metabolic phenotype, which is attributed to the increased mitochondrial DNA damage. ${ }^{[38]}$
In conclusion, there is evidence that NEIL1 might play an important role in ischemia stroke, but the exact functions of NEIL1 during the pathophysiologic development of cerebral ischemia are still unknown.

\section{NEIL2}

As previously mentioned, Rolseth et al. ${ }^{[35]}$ found that similarly to NEIL1, the expression of NEIL2 is not changed in response to OGD treatment in CA1. To date, we still know very little about the relationship between NEIL2 and ischemic stroke. Future studies are needed to completely understand if and how NEIL2 could be associated with ischemic stroke.

\section{NEIL3}

Similarly to NEIL1, the transcription of NEIL3 is significantly reduced in the hippocampus and cerebellum by hypothermia as observed in a study on newborn pigs exposed to hypoxia, however, no significant effect on the accumulation of oxidative DNA damage in genomic DNA was found. ${ }^{[36]}$ In order to understand the relationship between NEIL3 and hypoxia-ischemia, Sejersted et al. ${ }^{[29]}$ carried out an experiment on NEIL3 gene knockout (NEIL3-null) mice in vitro and in vivo. Interestingly, after hypoxia-ischemia, there is no increase of cellular damage or death in vivo in NEIL3-null mice at an early stage, but a significant deficient in reconstituted neuronal tissue after $42 \mathrm{~d}$. NEIL3-null neurospheres exhibited poor growth and skewed differentiation that could explain the poor outcome of NEIL3-null mice after hypoxic ischemia. In agreement with the aforementioned expression pattern, this study has demonstrated that NEIL3 seems to predominantly play a role in neurogenesis. NEIL3-null mice also showed learning and memory deficits and reduced anxiety-like behavior, and synaptic irregularities in hippocampal neurons. ${ }^{[31]}$ Future studies addressing the role of NEIL3 in neuronal tissue in ischemic stroke will shed more light on this issue.

\section{CONCLUSIONS AND FUTURE PERSPECTIVES}

As a consequence of high oxygen metabolism, an efficient BER pathway is activated to ensure genomic stability and brain homeostasis. NEILs have been discovered in 2002 and since then studies have reported that these proteins are mainly expressed in the brain. However, all these data have not clearly elucidated the expression pattern and the relationship between the changes in NEILs and ischemic stroke. Although, there is evidence that DNA glycosylases deficiency impacts on brain function in animal models, the molecular mechanism is still unknown. In the future, there is hope that by characterizing the effect of NEILs on subclasses 
of neurons, astrocytes, and microglia as well as other pathways of BER, we might be able to understand how NEILs contribute to ischemic stroke and find new targets for the treatment of ischemic stroke.

\section{Financial support and sponsorship}

Nil.

\section{Conflicts of interest}

There are no conflicts of interest.

\section{REFERENCES}

1. World Health Organization. The World Health Report 2002 - Reducing Risks, Promoting Healthy Life. Geneva: the Organization; 2002.

2. Donnan GA, Fisher M, Macleod M, Davis SM. Stroke. Lancet 2008;371:1612-23

3. Pradeep H, Diya JB, Shashikumar S, Rajanikant GK. Oxidative stress-assassin behind the ischemic stroke. Folia Neuropathol 2012;50:219-30.

4. Murin R, Drgova A, Kaplan P, Dobrota D, Lehotsky J. Ischemia/ reperfusion-induced oxidative stress causes structural changes of brain membrane proteins and lipids. Gen Physiol Biophys 2001;20:431-8.

5. Madamanchi NR, Vendrov A, Runge MS. Oxidative stress and vascular disease. Arterioscler Thromb Vasc Biol 2005:25:29-38.

6. Li P, Hu X, Gan Y, Gao Y, Liang W, Chen J. Mechanistic insight into DNA damage and repair in ischemic stroke: exploiting the base excision repair pathway as a model of neuroprotection. Antioxid Redox Signal 2011;14:1905-18.

7. Harrison JF, Hollensworth SB, Spitz DR, Copeland WC, Wilson GL, LeDoux SP. Oxidative stress-induced apoptosis in neurons correlates with mitochondrial DNA base excision repair pathway imbalance. Nucleic Acids Res 2005;33:4660-71.

8. Lubos E, Handy DE, Loscalzo J. Role of oxidative stress and nitric oxide in atherothrombosis. Front Biosci 2008;13:5323-44.

9. Wilson DM, $3^{\text {rd }}$, Bohr VA. The mechanics of base excision repair, and its relationship to aging and disease. DNA Repair (Amst) 2007;6:544-59.

10. Ide H, Kotera M. Human DNA glycosylases involved in the repair of oxidatively damaged DNA. Biol Pharm Bull 2004;27:480-5.

11. Krokan HE, Bjoras M. Base excision repair. Cold Spring Harb Perspect Biol 2013;5:a012583.

12. Liu Y, Prasad R, Beard WA, Kedar PS, Hou EW, Shock DD, Wilson SH. Coordination of steps in single-nucleotide base excision repair mediated by apurinic/apyrimidinic endonuclease 1 and DNA polymerase beta. $J$ Biol Chem 2007;282:13532-41.

13. Mandal SM, Hegde ML, Chatterjee A. Heode PM, Szczesny B, Banerjee D, Boldogh I, Gao R, Falkenberg M, Gustafsson CM, Sarkar PS, Hazra TK. Role of human DNA glycosylase Nei-like 2 (NEIL2) and single strand break repair protein polynucleotide kinase 3'-phosphatase in maintenance of mitochondrial genome. J Biol Chem 2012;287:2819-29.

14. Bosshard M, Markkanen E, van Loon B. Base excision repair in physiology and pathology of the central nervous system. Int $J$ Mol Sci 2012;13:16172-222.

15. Dou H, Mitra S, Hazra TK. Repair of oxidized bases in DNA bubble structures by human DNA glycosylases NEIL1 and NEIL2. J Biol Chem 2003;278:49679-84.

16. Hazra TK, Izumi T, Boldogh I, Imhoff B, Kow YW, Jaruga P, Dizdaroglu M, Mitra S. Identification and characterization of a human DNA glycosylase for repair of modified bases in oxidatively damaged DNA. Proc Natl Acad Sci U S A 2002;99:3523-8.

17. Hazra TK, Kow YW, Hatahet Z, Imhoff B, Boldogh I, Mokkapati SK, Mitra S, Izumi T. Identification and characterization of a novel human DNA glycosylase for repair of cytosine-derived lesions. J Biol Chem 2002;277:30417-20.
18. Morland I, Rolseth V, Luna L, Rognes T, Bjoras M, Seeberg E. Human DNA glycosylases of the bacterial Fpg/MutM superfamily: an alternative pathway for the repair of 8-oxoguanine and other oxidation products in DNA. Nucleic Acids Res 2002;30:4926-36.

19. Takao M, Kanno S, Kobayashi K, Zhang QM, Yonei S, van der Horst GT, Yasui A. A back-up glycosylase in Nth1 knock-out mice is a functional Nei (endonuclease VIII) homologue. JBiol Chem 2002;277:42205-13.

20. Dou H, Theriot CA, Das A, Hegde ML, Matsumoto Y, Boldogh I, Hazra TK, Bhakat KK, Mitra S. Interaction of the human DNA glycosylase NEIL1 with proliferating cell nuclear antigen. The potential for replication-associated repair of oxidized bases in mammalian genomes. J Biol Chem 2008;283:3130-40.

21. Banerjee D, Mandal SM, Das A, Hegde ML, Das S, Bhakat KK, Boldogh I, Sarkar PS, Mitra S, Hazra TK. Preferential repair of oxidized base damage in the transcribed genes of mammalian cells. J Biol Chem 2011;286:6006-16.

22. Liu M, Bandaru V, Bond JP, Jaruga P, Zhao X, Christov PP, Burrows CJ, Rizzo CJ, Dizdaroglu M, Wallace SS. The mouse ortholog of NEIL3 is a functional DNA glycosylase in vitro and in vivo. Proc Natl Acad Sci U S A 2010;107:4925-30.

23. Liu M, Doublie S, Wallace SS. Neil3, the final frontier for the DNA glycosylases that recognize oxidative damage. Mutat Res 2013;743-744:4-11.

24. Rolseth V, Runden-Pran E, Luna L, McMurray C, Bjoras M, Ottersen OP. Widespread distribution of DNA glycosylases removing oxidative DNA lesions in human and rodent brains. DNA Repair (Amst) 2008;7:1578-88.

25. Englander EW, Ma H. Differential modulation of base excision repair activities during brain ontogeny: implications for repair of transcribed DNA. Mech Ageing Dev 2006;127:64-9.

26. Gredilla R, Garm C, Holm R, Bohr VA, Stevnsner T. Differential age-related changes in mitochondrial DNA repair activities in mouse brain regions. Neurobiol Aging 2010;31:993-1002.

27. Torisu K, Tsuchimoto D, Ohnishi Y, Nakabeppu Y. Hematopoietic tissue-specific expression of mouse Neil3 for endonuclease VIII-like protein. J Biochem 2005;138:763-72.

28. Hildrestrand GA, Neurauter CG, Diep DB, Castellanos CG, Krauss S, Bjoras M, Luna L. Expression patterns of Neil3 during embryonic brain development and neoplasia. BMC Neurosci 2009;10:45.

29. Sejersted Y, Hildrestrand GA, Kunke D, Rolseth V, Krokeide SZ, Neurauter CG, Suganthan R, Atneosen-Asegg M, Fleming AM, Saugstad OD, Burrows CJ, Luna L, Bjoras M. Endonuclease VIII-like 3 (Neil3) DNA glycosylase promotes neurogenesis induced by hypoxia-ischemia. Proc Natl Acad Sci U S A 2011;108:18802-7.

30. Reis A, Hermanson O. The DNA glycosylases OGG1 and NEIL3 influence differentiation potential, proliferation, and senescence-associated signs in neural stem cells. Biochem Biophys Res Commun 2012;423:621-6.

31. Regnell CE, Hildrestrand GA, Sejersted Y, Medin T, Moldestad O, Rolseth V, Krokeide SZ, Suganthan R, Luna L, Bjoras M, Bergersen LH. Hippocampal adult neurogenesis is maintained by Neil3-dependent repair of oxidative DNA lesions in neural progenitor cells. Cell Rep 2012;2:503-10.

32. Whitfield ML, Sherlock G, Saldanha AJ, Murray JI, Ball CA, Alexander KE, Matese JC, Perou CM, Hurt MM, Brown PO, Botstein D. Identification of genes periodically expressed in the human cell cycle and their expression in tumors. Mol Biol Cell 2002; 13:1977-2000.

33. Bar-Joseph Z, Siegfried Z, Brandeis M, Brors B, Lu Y, Eils R, Dynlacht BD, Simon I. Genome-wide transcriptional analysis of the human cell cycle identifies genes differentially regulated in normal and cancer cells. Proc Natl Acad Sci U S A 2008;105:955-60.

34. Kauffmann A, Rosselli F, Lazar V, Winnepenninckx V, Mansuet-Lupo A, Dessen P, van den Oord JJ, Spatz A, Sarasin A. High expression of DNA repair pathways is associated with metastasis in melanoma patients. Oncogene 2008;27:565-73. 
35. Rolseth V, Runden-Pran E, Neurauter CG, Yndestad A, Luna L, Aukrust P, Ottersen OP, Bjoras M. Base excision repair activities in organotypic hippocampal slice cultures exposed to oxygen and glucose deprivation. DNA Repair (Amst) 2008;7:869-78.

36. Dalen ML, Alme TN, Bjoras M, Munkeby BH, Rootwelt T, Saugstad OD. Reduced expression of DNA glycosylases in post-hypoxic newborn pigs undergoing therapeutic hypothermia. Brain Res 2010;1363:198-205.

37. Canugovi C, Yoon JS, Feldman NH, Croteau DL, Mattson MP,
Bohr VA. Endonuclease VIII-like 1 (NEIL1) promotes short-term spatial memory retention and protects from ischemic stroke-induced brain dysfunction and death in mice. Proc Natl Acad Sci U S A 2012;109:14948-53

38. Vartanian V, Lowell B, Minko IG, Wood TG, Ceci JD, George S, Ballinger SW, Corless CL, McCullough AK, Lloyd RS. The metabolic syndrome resulting from a knockout of the NEIL1 DNA glycosylase. Proc Natl Acad Sci U S A 2006;103:1864-9. 